\title{
SOCIOECONOMIC CHARACTERISTICS OF EMIGRATION IN THE EARLY STAGE OF MODERNIZATION: PATH ANALYSIS BASED ON THE VILLAGE DATA IN JAPAN
}

\author{
Yoshio Kawamura
}

Ryukoku Extension Center, Ryukoku University \& Kyoto Prefectural College of Agriculture E-mail: yoshiokawamura@hotmail.com

Citation: Kawamura, Y. 2018. Socioeconomic Characteristics of Emigration in the Early Stage of Modernization: Path Analysis Based on the Village Data in Japan. J. Asian Rur. Stud. 2(1): 96-109

\begin{abstract}
International mobility of human beings is an important social phenomenon that demonstrates the degree of dynamism of a society. However, unlike many of European countries, Japanese emigrants to Hawaii, North America, South America and other Asian regions during the modernizing stage from the Meiji era to World War II were estimated as about one million at most; it might be said that the emigrants were exceptional as an illustration of labor force mobility. One characteristic fact of Japanese emigration is that home villages of emigrants are distributed very unevenly geographically. The paper deals with this geographically skewed distribution of villages inducing emigrants, clarifying what conditions of socioeconomic factors affect the emigration at the village level in the early stage of Japanese modernization. For the analysis, the dimensionality test by component factor analysis and path analysis are introduced, based on the secondary data which was published by the government in 1880 (Meiji 13) and then. The analysis clarifies that no single factor but several factors simultaneously affect the emigration at the village level, constructing the complex structure formed by three basic components: natural environment, accessibility of external resources and. socioeconomic characteristics.
\end{abstract}

Keywords: Japanese rural emigrants; socioeconomic characteristics of emigration; rural village economy; Meiji era as early stage of modernization

\section{Introduction}

Many studies of emigration from Japan indicate one characteristic that home villages of emigrants are distributed very unevenly. According to a study based on address data in files of ethnic Japanese living in Hawaii (1940) and in the continental US (1950), 29\% of all Japanese-Americans originated from Hiroshima Prefecture, 14\% from Yamaguchi Prefecture, and 13\% from Kumamoto Prefecture, followed by those from Okinawa Prefecture, Fukuoka Prefecture, and Wakayama Prefecture, each accounting for $6-7 \%$.

Figure 1 shows that home villages of overseas residents in the United States and Canada are decidedly located in southwestern regions: each prefecture of the regions produced these oversea emigrants more than the national average $(1 \%)$ of the total population. 


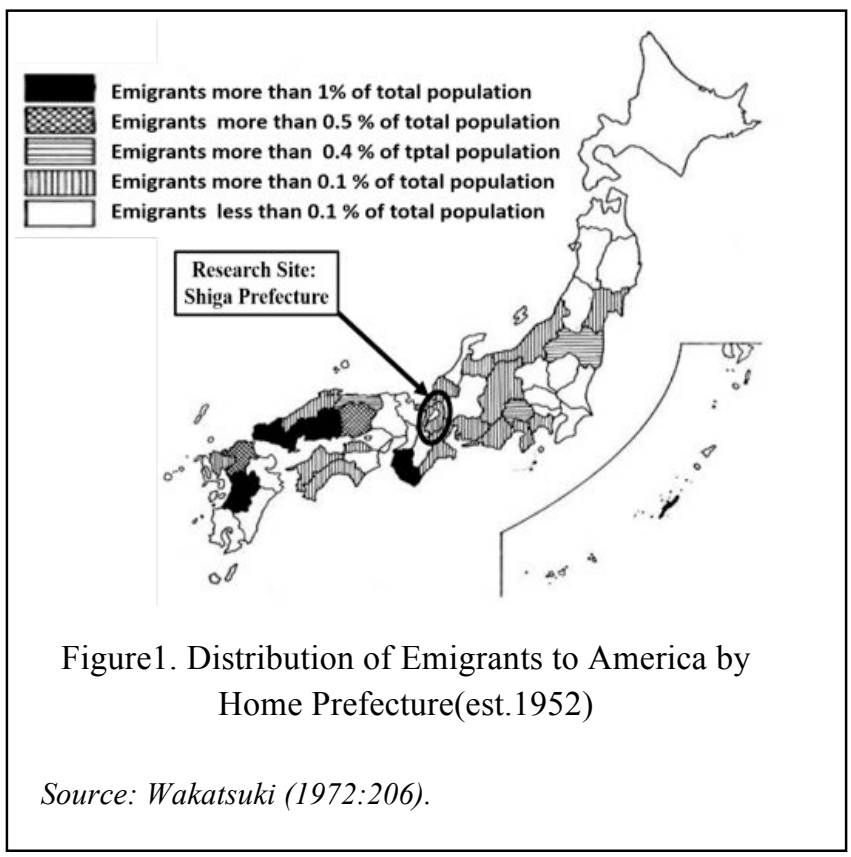

This regional imbalance in the oversea emigration is also observed at the village level within the same prefecture, suggesting the necessity of cross-sectional analyses based on comparison among those villages having produced many emigrants and other villages having produced less or no emigrants. In general, a village is the minimum local community which maintains relative social and economic homogeneity. Such homogeneity might be explained by external (locational) conditions of the village having nearly uniform influences to its residents. In other words, the primary industry, such as agriculture, which is the most fundamental economic element of village life, has a production structure directly influenced by natural locational conditions because deviation of natural conditions within the same village is slight. It is also considered that an economic entity (family unit, individuals) in a village shares nearly identical opportunities for employment in the association with economic location conditions. For example, because economic advantages and disadvantages of the primary industry being specified by a distance from the market are shared equally by farm families (or forestry and fishery families) in the village, it is considered that no significant differences exist in their opportunities in relation to work in this regard. The same applies to work opportunities (opportunities for side jobs) that are directly unrelated to the primary industry. Increased opportunities for side jobs brought by improved road conditions and promotion of urbanization will be enjoyed equally by all village residents. Consequently, natural and economic locational conditions existing as external conditions for the economy entity, for a village's constituent members, are deemed as nearly homogeneous throughout the village. Accordingly, deviation of work opportunities within the same village is mostly explained by differences of internal conditions (land, labour force, capital, etc.) of each economic entity, whereas deviation of opportunity of works among villages is mostly explained by differences of external conditions. 
The subject of this article is to clarify what conditions created a deviation between the villages having produced many emigrants and the villages having less or no emigrants in the Meiji era that was the early stage of Japanese modernization. The research is based on the data collected from the 113 villages in Inukami County in Shiga Prefecture which produced many emigrants. Regarding data related to emigrants (here defined as overseas travellers according to the passport status), those who had left from Inukami County for Hawaii, Canada, the United States, and Mexico during the Meiji era were extracted from among the records of passports issued and returned (List of Passports Issued and Returned) maintained by the Foreign Diplomacy Resource Centre and aggregated by village Most data related to the villages were collected from "Shiga Prefecture Product History" (Shiga Prefecture Municipality Development History Compilation Committee, "Shiga Prefecture Municipality Development History," 1962), which was published in 1880 (Meiji 13). The data shows the socioeconomic status of the villages several years before emigration, which began in the Meiji 10s.

\section{Method}

In addition to the number of emigrants from the village, which is the explained variable (Z001; dependent variable), 112 variables were collected as explanatory variables (independent variables). Contents of these variables include natural locational conditions of villages, distance from the city (market), transportation modes available (oxen, horses, wagons, ships), population, land-use by application, old specified crop, agricultural production, processing of agricultural products, consumption of agricultural products, fishery, forestry, mining, textiles, manufacturing, etc. The analyses were designed to extract variables that were associated directly with the number of emigrants (Z001) from among these 112 variables and to identify what direct relation these variables shared.

Figure 2 shows that analytical procedures used to accomplish this purpose consisted of four steps. For first analysis step (Step I), averages and standard deviations were measured for Z001 and the 112 variables and all of the variables were standardized, based on them. This step is a preparatory step towards the next analysis and, simultaneously, a basic analysis step for understanding concrete meanings of variables

In the second analysis step (Step II), simple correlation coefficients of independent variables with the dependent variable Z001 are measured and only variables having significant correlation coefficients at the significance level of $5 \%(\mathrm{p}<.05)$ are extracted. In this step, out of the 112 variables prepared as explanatory (independent) variables, 40 variables were found to have a statistically significant correlation with the dependent variable Z001. However, of them, three were excluded because either valid observation cases were few or important villages showed missing values. 
In the third analysis step (Step III), verification was made of which variables of 37 variables being extracted as explanatory variables should be handled as independent variables as they are, and which variables should be indexed as being of the same dimension. In the latter case, they would be converted or combined to produce new independent variables. In other words, this step is a dimensionality test of explanatory variables and a grouping of them based on the dimensionality test. The analytical method used for this purpose is common factoring method used most commonly among factor analysis methods; in addition, a varimax rotated factor matrix by orthogonal rotation was used for dimension determination of variables. Rotation was used for dimension determination because a more simplified factor structure is obtained using it and clearer grouping of variables is possible. To determine whether variables can be grouped with identical dimensionality led to a judgment of whether they are loaded to the same factor: a factor coefficient of more than 0.7 was used as the reference threshold.

Using this reference, more than half $(49 \%)$ of the total variance of

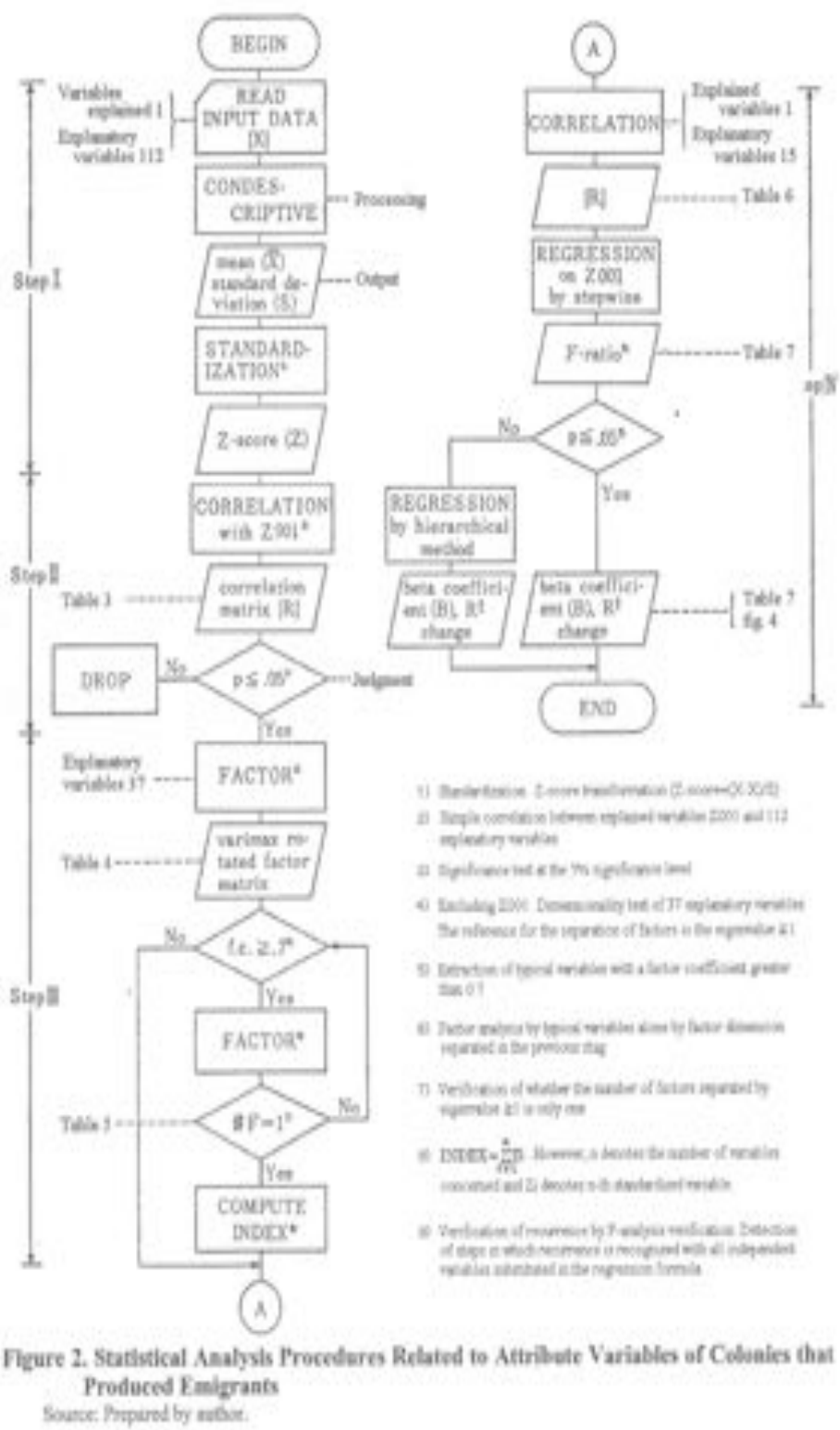
variables is explained by specific factors. It was therefore strongly correlated with corresponding factors, and a plurality of variables was handled as the same dimensionality. In this step, although 37 variables separated out 7 factors: 11 variables were strongly correlated with the first factor (FAC11); 8 variables were correlated with second factor (FAC12); 4 variables and 3 variables were correlated, respectively, with the third factor (FAC13) and fourth factor (FAC14). For the other factors, the existence of a plurality of variables reaching the reference was not observed. Therefore, 26 variables correlated strongly with four factors from the first factor to the fourth factor were indexed by adding variables related to each of the groups: 26 variables were converted to new 4 variables according to this indexing. The remaining 11 variables were considered as independent variables and used for subsequent analyses. 
Consequently, as many as the 112 explanatory variables used initially were reduced to 15 variables ( 4 indices +11 variables), thereby attaining simplification.

In the fourth analysis step (Step IV), as of 15 explanatory variables, verification was made to identify variables having a direct relation to the dependent variable Z001. To do so, the path analysis method, which is a multiple standardized regression analysis method, was used because the path coefficients indicate the degree of direct influences of the independent variable on the dependent variable. In this path analysis model, among the 15 variables of explanatory variables, 8 variables were defined as independent variables and 7 variables were defined as mediation variables. Therefore, the path analysis equations were defined as follows:

$$
\begin{aligned}
Z_{001} & =\sum_{j} P_{\left(Z_{\mathrm{OO} 1}, Y_{j}\right)} Y_{j}+\sum_{i} P_{\left(Z_{\mathrm{OO} 1}, X_{i}\right)} X_{i}+\epsilon_{Z_{\mathrm{oO} 1}} \\
Y_{s} & =\sum_{j \neq s} P_{\left(Y_{s}, Y_{j}\right)} Y_{j}+\sum_{i} P_{\left(Y_{s}, X_{i}\right)} X_{i} s+\epsilon_{s}
\end{aligned}
$$

where $\mathrm{Z} 001$ is the dependent variable, $\mathrm{X}_{\mathrm{i}}$ is an independent variable and $\mathrm{Yj}$ is an intermediate variable which functions as an explanatory variable to $\mathrm{Z} 001$ and also functions as a dependent variable explained by other $\mathrm{Yj}_{\mathrm{j}}$ and $\mathrm{X}_{\mathrm{i}}$. $\mathrm{P}$ indicates a path coefficient which is a standardized regression coefficient $(B)$ and $\varepsilon$ is an erratum.

\section{Result and Discussion}

\subsection{Distribution of Villages with Overseas Emigrants}

According to records in the Foreign Diplomacy Resource Centre of the Ministry of Foreign Affairs, 2,647 people in all were confirmed as overseas travellers to the United States and Canada from Inukami County in Shiga Prefecture that county during the Meiji era. A breakdown of this figure is $61 \%$ to Canada; second place is $21 \%$ to Hawaii, $16 \%$ to the continental U.S., and the remaining only $2 \%$ to Mexico because the majority of travellers to Mexico relocated to the United States of America. Furthermore, 500 of these overseas travellers were performing re-entry. Consequently, one out of five who travelled for the first time overseas (hereinafter, referred to simply as oversea travellers) went overseas again.

Table 1 presents this situation of emigrants at the 113 villages in Inukami County in the Meiji era. The table shows that the average village of the county at that time produced 19.0 oversea travellers and 4.5 re-entrants producing $24 \%$ as re-entrant ratio. The ratio of these oversea travellers in the village population (hereinafter designated as the emigrant ratio) is less than $5 \%$, the number of travellers and re-entrants per household (hereinafter designated as the number of emigrants per household) is 0.2 , which means that every five households has one emigrant in the village.

At the same time, the table show a great diversity of emigrants along with villages. There were villages with zero oversea travellers while one village produced almost 400 emigrants and another produced more than 100 re-entrants. The extremely high simple correlation coefficient $(r)$ between oversea travellers and re-entrants at the village level indicates that the distribution of oversea travellers by villages and the same of reentrants are markedly similar. An exactly equivalent trend is observed as to the emigrant ratio and the number of emigrants per household. The village that exhibited the maximum for the former produced travellers and re-entrants corresponding to $45 \%$ of 
the population; the village which exhibited the maximum for the latter produced travellers and re-entrants of 2.3 people per household, whereas the village distribution of both is strikingly similar; their correlative relations are extremely strong, as if the same variations were used.

Table 1. Correlation between number of oversea travellers and Emigration Ratio (Inukami County, Shiga Prefecture, Meiji Era)

\begin{tabular}{|c|c|c|c|c|c|c|c|c|c|}
\hline \multicolumn{2}{|c|}{ Variable } & \multirow{2}{*}{$\begin{array}{c}\text { Observat } \\
\text { ion }\end{array}$} & \multirow{2}{*}{$\begin{array}{l}\text { Averag } \\
\text { e }\end{array}$} & \multirow{2}{*}{$\begin{array}{l}\text { Maximu } \\
\mathrm{m}\end{array}$} & \multirow{2}{*}{$\begin{array}{l}\text { Minim } \\
\text { um }\end{array}$} & \multirow{2}{*}{$\begin{array}{r}\text { Standard } \\
\text { Deviation }\end{array}$} & \multicolumn{3}{|c|}{$\begin{array}{l}\text { Simple Correlation } \\
\text { Coefficient }(r)^{1)}\end{array}$} \\
\hline Name & Contents & & & & & & Z002 & Z011 & Z012 \\
\hline Z001 & $\begin{array}{lr}\begin{array}{l}\text { Number of } \\
\text { Travellers } \\
\text { Travel Only) }\end{array} & \text { (First-time } \\
\end{array}$ & 113 & 19 & 382 & 0 & 46.04 & $\begin{array}{l}0.96 \\
8\end{array}$ & 0.488 & 0.870 \\
\hline Z002 & Number of Reentrants & 113 & 4.5 & 136 & 0 & 15.8 & 1 & $\begin{array}{l}0.85 \\
9\end{array}$ & 0.882 \\
\hline Z011 & $\begin{array}{ll}\text { Emigrant } & \text { Ratio } \\
\text { (Z001/Village } & \\
\text { Population) } & \end{array}$ & 107 & 4.4 & 44.8 & 0 & 7.14 & - & 1 & 0.986 \\
\hline Z012 & $\begin{array}{l}\text { Number of Emigrants } \\
\text { per } \\
\text { (Z001/Number of Village } \\
\text { Households) }\end{array}$ & 107 & 0.19 & 2.25 & 0 & 0.33 & - & - & 1 \\
\hline
\end{tabular}

1)Significance level of $\mathrm{r}: \mathrm{p}<0.01$.

Sources: Number of oversea travellers and re-entrants are collected from "List of Passports Issued and Returned" (Diplomatic Record Office of the Ministry of Foreign Affairs: Archive).Commoner population and number of commoner houses are derived from data in the "History of Shiga Prefecture Commercial Products"(Editing Committee, History of Municipalities in Shiga Prefecture,1962)

However, although correlation coefficients between the number of travellers and reentrants, and the emigrant ratio and number of emigrants per household are very high for either item, it is suggested that some differences of village distribution exist between these groups. If a reference threshold of villages producing many emigrants were specified as having more than 50 travellers, more than 10 people for the re-entrants, more than $10 \%$ of the population for the emigrant ratio, and more than 0.5 people for the number of emigrants per household, then villages exceeding all of these four variables' threshold values would be only six villages:(Hatsusaka, Ooyabu, Kaideima, Sugoshi, Kiyosaki and Mitsuya). Five villages (Hinatsu, Hikone, Matsubara, Tsuchida, and Kanro) exceeded only the reference of the number of travellers and reentrants. Six villages (Uo, Tsujidou, Nose, Ichien, Toga, and Mukinokura) exceeded only the reference of the emigrant ratio and number of emigrants per household. Although it might be readily apparent, 11 villages of the former two groups have a large population, but 6 villages of the latter group have a small population.

Figure 3 depicts the geographical locations of these villages. Five villages (Matsubara, Ooyabu, Hatsusaka, Sugoshi, and Mitsuya) are located at beach ridge district at lakefront. Five villages (Hikone, Kaideima, Kanro, Hinatsu, and Kiyosaki) are in plain districts adjoining the beach ridge district. The four villages of Toga, Nose, Uo, and Tsujido are in the plain district somewhat to the midland side. Three villages (Tsuchida, Ichien, and Mukainokura) are at the east end of the plain district, continuing to the mountainous area. Of these 17 villages, those recorded in the "Shiga Prefecture 
Product History" as having had flood damage are only eight villages, including all five villages in the beach ridge district, Kanro and Kiyosaki at the plain district from the lakefront, and Uo at the slightly inland side. However, regarding the six villages such as Hatsusaka, where the emigration ratio is remarkable in absolute number and population ratio, five villages are in locations with conditions being damaged by flooding. Consequently, it is possible to cite flood damage as a direct reason for emigration from these districts. Nevertheless, the adequacy of this might be true only for villages in the location conditions that had undergone flood damage because more than half of the 17 villages in Inukami County are in locations that are unaffected by flood damage, suggesting that it is inappropriate to consider flood damage as a general explanation for migrants in this region. In fact, although Fig. 3 shows that a certain level of correlative relation exists between emigrant status in the village and geographical conditions of the village, for investigation of whether geographical conditions constitute a general direct reason for emigration, analyses from another perspective will be necessary.

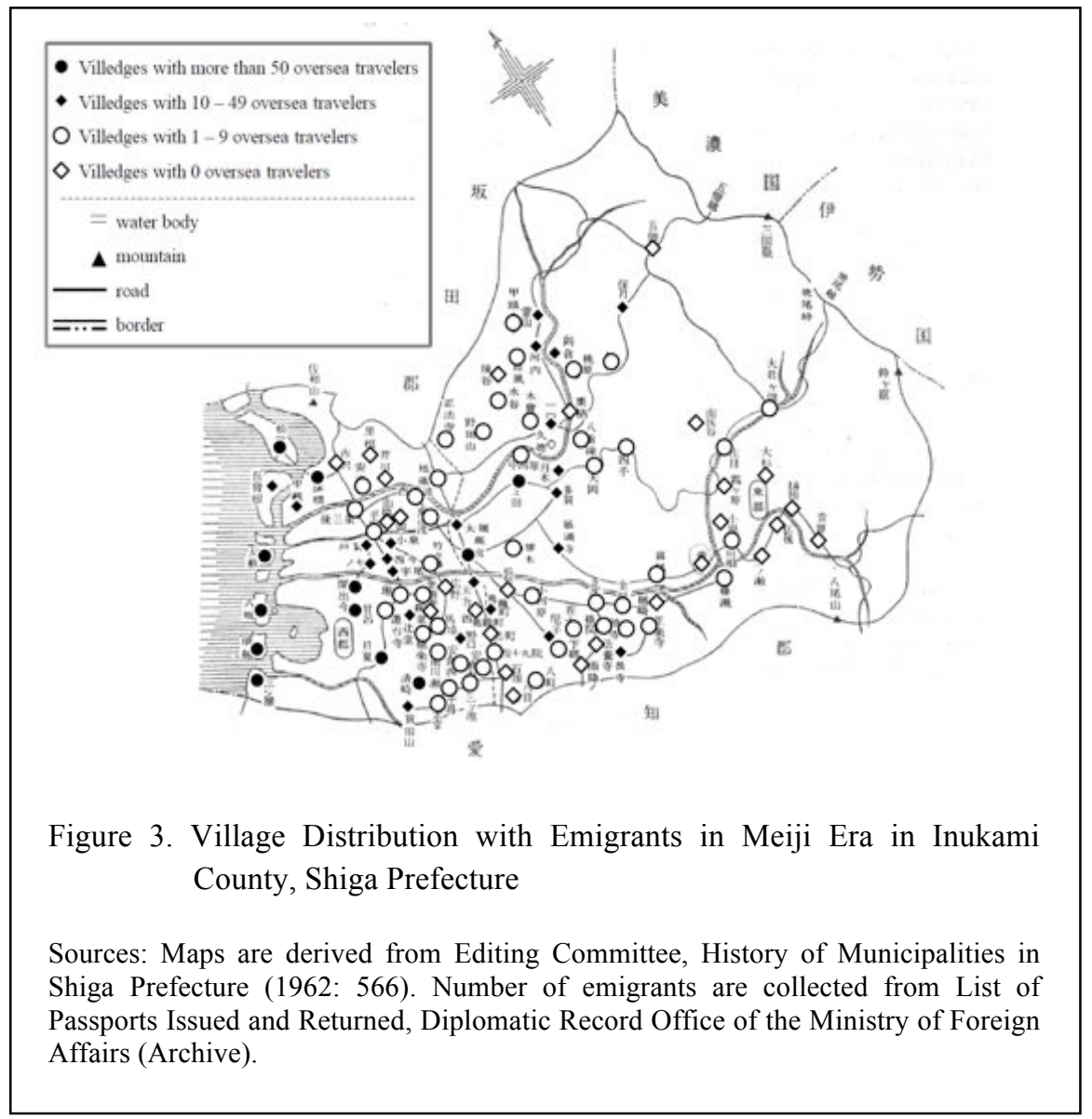

\subsection{Dimensionality Test of Socioeconomic Attributes in Emigrant Villages}

As explained in the section of analysis method, 37 variables were determined as explanatory variables which have statistically significant correlations with the dependent variable Z001. These 37 variables were tested for their dimensionality 
through factor analysis. Table 2 shows that the factor analysis produced 7 factors from the 37 variables. However, the first four factors are only valid for the dimensionality because the judgement of grouping variables as one dimension is the plurality of variables strongly loading on the corresponding factor with higher than 0.7 factor coefficient.

The first factor was strongly formed by 11 variables: Y023 (number of farm families), Y0411 (rice field area), Y0412 (rice field price), Y051 (village money stock for contingency), Y0611 (crop acreage of ordinary cooking rice), Y0612 (production of ordinary cooking rice), Y0613 (consumption of ordinary cooking rice), Y0621 (crop acreage of sticky rice), Y0622 (production of sticky rice), Y0623 (consumption of sticky rice), and Y0643 (consumption of wheat). These 11 variables are strongly enough correlated each other to form the same dimension creating one index FAC11 which indicates the meaning of village economic power based on rice crop.

The second factor was strongly formed by 8 variables: Y031 (old specified crop), Y022 (population of ordinary-class people), Y024 (households of samurai-class people), Y025 (households of merchants), Y0431 (housing land area), Y0432 (housing land price), Y055 (number of wagons owned), and Y1111 (production of manufacture). These 8 variables are strongly enough correlated each other to form the same dimension creating one index FAC12 which indicates the meaning of urban elements in village.

The third factor was strongly formed by 4 variables: Y0421 (cultivated field area), Y0422 (cultivated field price), Y054 (number of boats owned), and Y0731 (production of indigo). These 4 variables are strongly enough correlated each other to form the same dimension creating one index FAC13 which indicates the meaning of beach-ridge upland farming economy. The forth factor was strongly formed by 3 variables: Y0631 (barely crop acreage), Y0632 (production of barely), and Y0633 (consumption of barely). These 3 variables are strongly enough correlated each other to form the same dimension creating one index FAC14 which indicates the meaning of barely production.

Table 2. Dimensionality Test of Colony Attribute Variables by Factor Analysis (Inukami County, Shiga Prefecture, Meiji Era)

\begin{tabular}{|c|c|c|c|c|c|c|c|c|c|c|}
\hline \multirow{2}{*}{$\begin{array}{l}\text { Variabl } \\
\mathrm{e}\end{array}$} & \multicolumn{9}{|c|}{ FACTOR COEFFICIENTS } & \multirow{2}{*}{$\begin{array}{l}\text { Comm } \\
\text { unality }\end{array}$} \\
\hline & $\begin{array}{c}\text { Factor } \\
1\end{array}$ & & $\begin{array}{c}\text { Factor } \\
2\end{array}$ & & $\begin{array}{c}\text { Factor } \\
3\end{array}$ & $\begin{array}{c}\text { Factc } \\
4\end{array}$ & $\begin{array}{r}\text { Fact } \\
5\end{array}$ & $\begin{array}{r}\text { Fact } \\
6\end{array}$ & $\begin{array}{c}\text { Factor } \\
7\end{array}$ & \\
\hline Y023 & 0.745 & $*$ & 0.004 & & 0.497 & 0.049 & 0.122 & -0.003 & 0.083 & 0.827 \\
\hline Y0411 & 0.928 & $*$ & 0.001 & & 0.113 & 0.169 & 0.161 & 0.225 & 0.069 & 0.985 \\
\hline Y0412 & 0.899 & $*$ & -0.001 & & -0.005 & 0.256 & 0.156 & 0.275 & 0.040 & 0.977 \\
\hline Y051 & 0.811 & $*$ & 0.420 & & 0.103 & 0.246 & 0.166 & 0.203 & -0.065 & 0.980 \\
\hline Y0611 & 0.915 & $*$ & 0.001 & & 0.117 & 0.159 & 0.162 & 0.253 & 0.121 & 0.983 \\
\hline Y0621 & 0.894 & $*$ & 0.022 & & -0.063 & 0.217 & 0.053 & -0.050 & 0.187 & 0.892 \\
\hline Y0612 & 0.896 & $*$ & 0.006 & & 0.116 & 0.162 & 0.166 & 0.280 & 0.193 & 0.987 \\
\hline Y0622 & 0.886 & $*$ & 0.028 & & -0.055 & 0.218 & 0.048 & -0.041 & 0.232 & 0.896 \\
\hline Y0613 & 0.915 & $*$ & 0.035 & & 0.229 & 0.126 & 0.095 & 0.211 & 0.096 & 0.971 \\
\hline Y0623 & 0.896 & $*$ & 0.041 & & 0.126 & -0.054 & 0.117 & -0.068 & 0.127 & 0.858 \\
\hline Y0643 & 0.804 & $*$ & 0.047 & & -0.027 & 0.251 & 0.154 & -0.293 & -0.095 & 0.832 \\
\hline Y021 & -0.122 & & 0.989 & $*$ & 0.025 & 0.019 & 0.022 & 0.038 & 0.002 & 0.996 \\
\hline Y022 & 0.205 & & 0.969 & $*$ & 0.118 & -0.130 & 0.034 & -0.027 & 0.029 & 0.998 \\
\hline Y024 & -0.077 & & 0.994 & $*$ & 0.036 & 0.003 & 0.028 & 0.023 & -0.008 & 0.996 \\
\hline Y025 & 0.016 & & 0.995 & $*$ & 0.000 & -0.038 & 0.009 & -0.011 & 0.004 & 0.992 \\
\hline
\end{tabular}




\begin{tabular}{|c|c|c|c|c|c|c|c|c|c|c|c|c|c|}
\hline Y0431 & 0.081 & 0.991 & * & 0.066 & & 0.014 & & 0.031 & & 0.035 & & 0.008 & 0.995 \\
\hline Y0432 & 0.149 & 0.984 & * & 0.046 & & -0.035 & & 0.030 & & -0.006 & & 0.000 & 0.997 \\
\hline Y055 & 0.543 & 0.708 & * & -0.066 & & 0.170 & & 0.082 & & -0.137 & & -0.158 & 0.881 \\
\hline Y1111 & -0.051 & 0.970 & $*$ & 0.103 & & -0.026 & & 0.058 & & -0.033 & & 0.005 & 0.959 \\
\hline Y0421 & 0.274 & 0.137 & & 0.780 & * & -0.093 & & -0.250 & & -0.039 & & -0.138 & 0.796 \\
\hline Y0422 & 0.509 & 0.131 & & 0.797 & * & -0.056 & & 0.000 & & 0.079 & & 0.017 & 0.921 \\
\hline $\begin{array}{l}\text { Y054 } \\
\end{array}$ & -0.030 & 0.076 & & 0.890 & * & 0.061 & & 0.115 & & -0.152 & & 0.183 & 0.873 \\
\hline Y0731 & 0.085 & -0.022 & & 0.869 & * & 0.093 & & 0.114 & & -0.005 & & -0.005 & 0.786 \\
\hline Y0631 & 0.502 & -0.006 & & 0.143 & & 0.786 & $*$ & -0.008 & & 0.081 & & -0.037 & 0.903 \\
\hline Y0632 & 0.555 & 0.004 & & 0.095 & & 0.786 & * & 0.029 & & 0.057 & & 0.197 & 0.978 \\
\hline Y0633 & 0.524 & -0.000 & & 0.136 & & 0.786 & * & -0.037 & & 0.009 & & 0.242 & 0.972 \\
\hline Y012 & 0.287 & 0.086 & & 0.063 & & 0.027 & & 0.811 & * & 0.136 & & 0.216 & 0.818 \\
\hline Y0614 & 0.269 & -0.045 & & -0.144 & & 0.115 & & 0.177 & & 0.829 & * & 0.220 & 0.877 \\
\hline Y0685 & 0.246 & 0.044 & & -0.002 & & 0.102 & & 0.333 & & 0.135 & & 0.571 & 0.529 \\
\hline Y017 & 0.196 & -0.054 & & -0.057 & & 0.059 & & 0.254 & & -0.108 & & -0.119 & 0.139 \\
\hline Y0711 & 0.106 & -0.034 & & 0.300 & & 0.202 & & 0.194 & & 0.124 & & 0.116 & 0.210 \\
\hline Y0811 & -0.042 & 0.254 & & 0.525 & & 0.194 & & 0.191 & & -0.046 & & 0.221 & 0.468 \\
\hline Y0462 & 0.500 & 0.094 & & 0.099 & & -0.067 & & 0.079 & & 0.139 & & -0.093 & 0.308 \\
\hline Y0661 & 0.622 & 0.016 & & 0.168 & & 0.168 & & -0.003 & & 0.024 & & 0.031 & 0.445 \\
\hline Y0091 & -0.152 & 0.030 & & -0.169 & & -0.091 & & -0.097 & & -0.074 & & -0.384 & 0.223 \\
\hline Y016 & 0.015 & -0.058 & & 0.401 & & 0.049 & & -0.110 & & 0.020 & & 0.387 & 0.329 \\
\hline XA052 & -0.146 & -0.161 & & -0.150 & & 0.081 & & -0.527 & & -0.092 & & -0.116 & 0.377 \\
\hline
\end{tabular}

Notes: 1) Structure by varimax rotation in factor analysis by PA2.

2) An asterisk* denotes those with factor coefficient greater than 0.7 .

Source: Prepared by the author.

Therefore, 26 variables correlated strongly with the four factors from the first factor to the fourth factor were indexed by adding variables related to each of the groups: that is, 26 variables were converted into new 4 variables (indices) according to this indexing. The remaining 11 variables were considered as individual independent variables and used for subsequent analyses. Those remaining 11 variables are as follows:

(a) XA052 (road distance to Hikone, the county capital)

(b) Y012 (advantageousness of geographical features such as flat, hilly, and mountainous)

(c) Y016 (presence/absence of flood damage)

(d) Y017 (presence/absence of drought damage)

(e) Y0462 (miscellaneous land price)

(f) Y0685 (wheat crop field productivity)

(g) Y0614 (ordinary cooking rice supply and demand balance)

(h) Y0661 (soybean crop acreage)

(i) Y0711 (oil-seed production volume)

(j) Y0811 (presence/absence of fishery production)

(k) Y0911 (textile production)

Consequently, as many as the 112 explanatory variables used initially were reduced to 15 variables ( 4 indices +11 variables), thereby attaining simplification.

Out of the above 11 variables, four variables, (a) XA052 (road distance to Hikone, the county capital), (b) Y012 (advantageousness of geographical features such as flat, hilly, and mountainous, (c) Y016 (presence/absence of flood damage) and (d) Y017 (presence/absence of drought damage), are variables indicating locational conditions 
surrounding villages. The variable of (f) Y0685 (wheat crop field productivity) is a variable indicating soil fertility directly related with the natural environment and thus can be considered as a variable indicating a locational condition of villages. The variable of (e) Y0462 (miscellaneous land price) is also considered as a variable locational condition of village since the land price is significantly related to urbanization. These six variables and two indices of FAC12 (urban element) and FAC13 (beach-ridge upland farming economy) were determined as exogenous variables which function as environmental conditions for the village residents. The relations among those eight exogenous variables are shown in Fig. 4 of the following section. Therefore, out of the 15 explanatory variables to the dependent variable of Z001, the above eight variables are exogenous variables in the model. The remaining seven variables are endogenous variables which are functioning as mediation variables in the model.

\subsection{Path Analysis of Socioeconomic Factors on Emigration}

In order to clarify direct impacts of the 15 explanatory variables on the dependent variable Z001, path analysis method was introduced as mentioned in the previous section of analysis method. The method is a multiple linear standardized regression analysis and this time stepwise method was applied. In this path analysis model, 7 variables were defined as mediation variables out of the 15 variables of explanatory variables. Therefore, seven path analysis equations were introduced for the mediation variables, according to the definition (equation 2 in the analysis method section), and one path equation for the dependent variable z001, according to the definition (equation 1 in the analysis method section). The result of these path equations are shown in Fig 4 of the path diagram which clarifies the direct impacts of explanatory variables on the dependent variable Z001, emigrants (oversea travellers) from Inulami County to North America including Hawaii in the Meiji ear.

As shown in Fig. 4, when two variables $\mathrm{X}$ and $\mathrm{Y}$ are expressed as $\mathrm{X}-\mathrm{Y}$, a simple correlative relation between $\mathrm{X}$ and $\mathrm{Y}$ is shown; their numerals show a simple correlation coefficient, whereas an arrow from $\mathrm{X}$ to $\mathrm{Y}$ shows those related to direct influences from $\mathrm{X}$ to $\mathrm{Y}$, and their numerals show a path coefficient. A disturbance is represented by e; the square of this numeral represents the portion that is not explained by the model. The relation between mediation variables is premised on a concurrent mutual cooperative relation. Therefore, those related to direct mutual influences are normally recognized in the form of two opposite directional arrows between $\mathrm{X}$ and Y. However, it is common that the intensity of these two direct influences differs; therefore, when those related to direct influences of one side are so weak and significant value cannot be taken, those related to direct influence between both variables will be in one direction. Those related to one-sided direct influences are detected between some of mediation variables in Fig. 4 。

The path diagram shows six explanatory variables are directly affecting Z001: FAC13 (beach-ridge upland farming economy: $\mathrm{P}=.36$ ), Y0661 (soybean crop acreage: $\mathrm{P}=.34$ ), Y0811 (presence/absence of fishery production: $\mathrm{P}=.25$ ), $\mathrm{Y} 0911$ (presence/absence of textile production: $\mathrm{P}=-.20$ ), $\mathrm{Y} 017$ (presence/absence of drought damage: $\mathrm{P}=-.20$ ), and $\mathrm{Y} 0614$ (ordinary cooking rice supply and demand balance: $\mathrm{P}=.15$ ). Here, $\mathrm{P}$ indicates a path coefficient between the dependent variable $\mathrm{Z} 001$ and an 
explanatory variable and a number means a direct impact of an explanatory variable. For example, the path coefficient of FAC13 on Z001 (P=.36) means $36 \%$ of the total change of FAC13 converted into a direct impact on Z001. By these six variables, $69 \%$ of the total variance of Z001 is explained $\left(1-\mathrm{e}^{2}=1-(.56)^{2}\right)$ which indicates quite high percentage of explanation by the model.

Accordingly, the most important variable among these six explanatory variables is the beach ridge upland farming economy (FAC13) which has a moderate correlation with an independent variable of presence/absence of flood damage (Y016). This indicates that a flood indirectly impacts to Z001 through FAC13. In addition, FAC13 directly affects the variable of presence/absence of fishery production (Y0811) which has a direct impact on Z001. At the same time, a variable of presence/absence of drought damage (Y017) directly impacts to Z001. Those results clearly indicate the significant influence of natural condition and disaster (flood and drought) on the emigration.

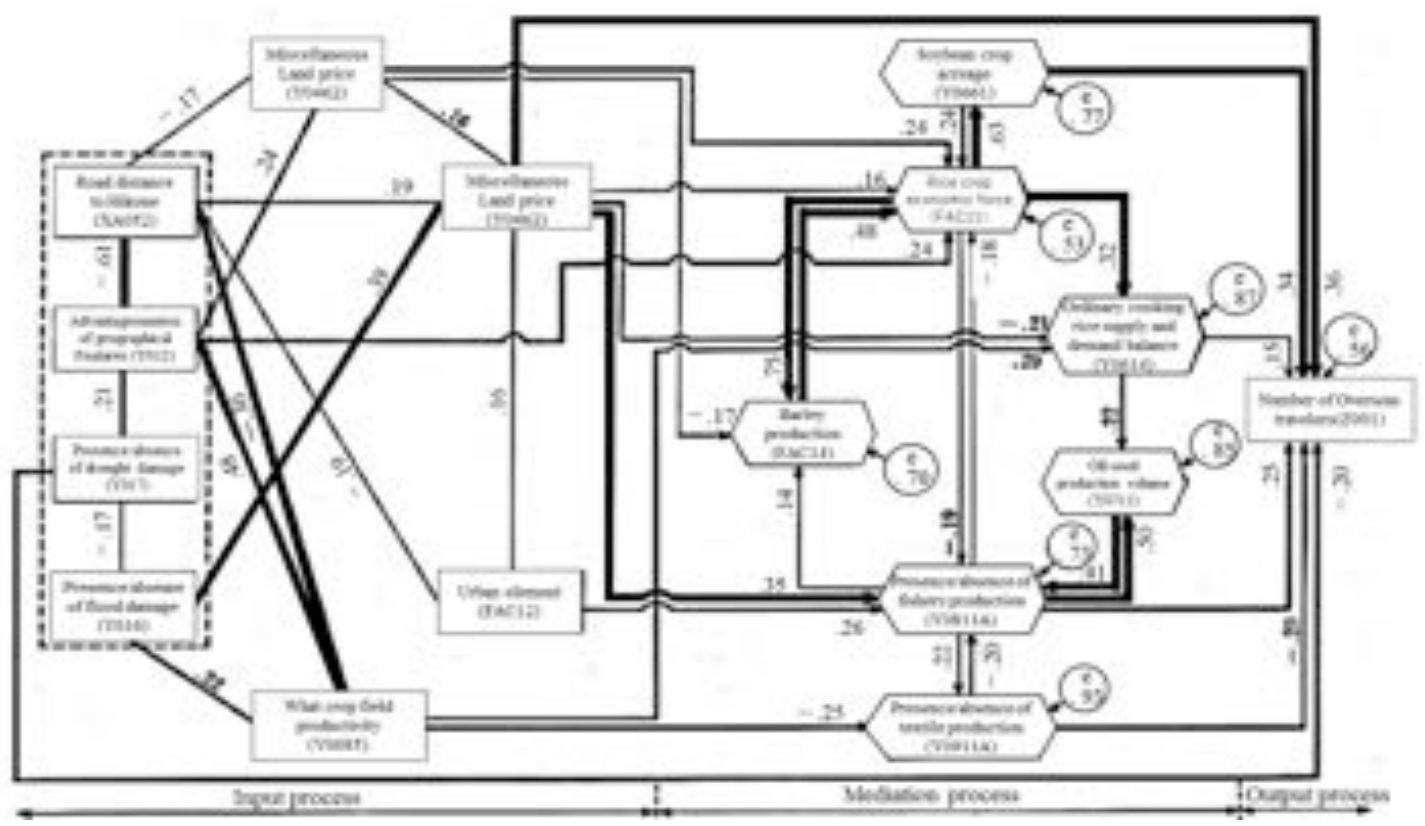

Figure 4. Path Diagram of Emigrant Structure at the Village Level

(Inukami County, Shiga Prefecture, Meiji Era)

Notes: A dash (-) denotes correlation; numerals denotes a simple correlation coefficient that is significant at the 5\% significant level. The arrow $(\rightarrow$ )signifies a direct influence on which the arrow is pointing, and numerals show as significant path coefficient that is significant at the $5 \%$ significance level.

Letter $e$ denotes a change variable (disturbance) of each variable: its square denotes a portion of the dependent variable that is not explained by the model.

Source: Prepared by the author., 
The second but almost equally important variable impacting on Z001 is the variable of soybean crop acreage (Y0661). Soybean was one of important cash crop in this area and Y0661 is strongly affected by the variable of rice crop economic power (FAC11) that indicates the fundamental economic power of village based on rice production and thus occupies the central position in the mediation structure in this path diagram: FAC11 has direct impacts on not only Y0661 but also FAC14, Y0614 as well as Y0811. This means that FAC11 indirectly affects Z001 from many aspects through the impact linkages with the variable of soybean crop acreage (Y0661), the variable of ordinary cooling rice supply and demand balance (Y0614) and the variable of presence/absence of fishery production (Y0811). These results indicate that the emigration was strongly associated with wealthy condition of agricultural economy at the village level. The last variable directly impacting the emigration is the variable of presentation/absence of textile production. However, the path coefficient of this variable ( $\left.\mathrm{P}^{\prime}-.20\right)$ indicates the less emigration in the villages having the more textile production. These results are probably indicating that, in the case of village having textile industry, village economy was somehow stable and strong enough not to produce emigrants but that, in the case of village strongly relying on agriculture or fishery, emigration was one of important choices for the village people to get better economic condition especially when they were suffered by flood/drought or economic destruction in firming.

\section{Discussion on Research Outputs}

The path diagram in Figure 4 shows the complexity of emigration causality constructed by the three basic components at the village level: natural environment, economic characteristics and external accessibility to external resources.

First, the natural environment is functioning as one of the basic factors to affect the motivation of emigrants. The village operating a beach-ridged upland farming economy, which had fishery production and was related to the presence of flood damage, produced more emigrants. In other words, the more possibility of flood damage, the more emigrants were produced. This means that flood damage affects negatively people's life and thus it pushes people's emigration. However, on the other hand, a village having the less possibility of drought damage, the more emigrants were produced. The less possibility of drought damage related to the better geographical conditions where the rice crop economic force of a village was relatively strong and was associated with the larger soybean crop acreage. The soybean crop acreage directly associated with emigration at the village. This means that the richer of village economy based on rice crop, the more emigrants were produced. These results indicate that even natural environments affect people's decision making as to emigration differently according to different economic conditions at the village level.

Second, the economic characteristics at the village level are functioning as one of the basic factors to affect the motivation of emigrants. The villages depending on fishery production, which were located at lake-coastal area, produced more emigrants and those villages were operating beach-ridge upland farming. The villages having large soybean crop acreage, which were located at good natural environments, produced more emigrants and those villages had strong rice crop economy which was the most important base of village economy at that time. Those results indicate the importance of primary economy as a basic factor to affect emigration at the village level. which is 
directly associated with the natural environment condition, The villages depending on textile production produced less emigrants, indicating their stable economy at the village level not depending on the primary production which might have negative direct impacts from change of natural environments, In fact, the villages hiving textile production were located at the area having more possibility of droughts and relatively poor soil. Thus, the villages had weak rice crop economy which was the most important base of village economy at that time, and developed textile production.

Third, the external accessibility such as access to roads, markets and urban centers at the village level are functioning as one of the basic factors to affect the motivation of emigrants. Although no factors of external access had direct impacts on emigration, the characteristics of village economy directly affecting emigration had significant association with those factors of external resources. For example, soybean was one of typical commercialized crops; and beach-ridge upland farming, which produced vegetables, and fishery production also required direct marketing to urban sector. The characteristics of village economy directly impacting emigration are strongly associated with commercialized economy which is realized through open access to external resources including markets. This indicates that the more emigrants are produced in the more open-accessed advanced economy, where intercommunications with external societies take place frequently, rather than in the self-sufficient, closed, lesserdeveloped economy. Although access with external resources is specified by developments of transportation modes and information access, this is a prior condition not only for physical commercialization in economy but also for acquisition of knowledge about overseas countries and emigration.

However, it should be noted that the value systems such as evaluating economic conditions as well as performance orientation at the individual level are functioning as the fourth basic components to affect the motivation of emigrants, although those are invisible and internal factors. The association between emigration and well-being of village economy indicates the relative poverty as a factor affecting emigration rather than the absolute poverty although it is common to mention the poverty as a fundamental factor for emigration. The relative poverty means the poverty based on the emigrant's recognition that, instead of indicating a lower economic level itself, the realized economic level is merely lower than the conventional economic level because of natural disasters, variation of external economy such as price and economic destruction, and/or an income difference recognized from comparison with economically advanced cases, even if the conventional economical level is attained. Emigration can be realized through the value of performance orientation associated with this recognition of gap between realized and expected economic conditions.

\section{Conclusion}

The previous studies on Japanese emigration from rural areas to other countries, especially the north America, are based on research approaches of history and/or sociological studies. The studies clarify that the situation of emigration is directly affected by the international relations around Japan as well as tense relations between the value and behavior of Japanese emigrants and those of the receiving society. However, emigration itself results from the personal initiative of an emigrant and thus it is important to understand emigration as collective phenomena of individuals. In this 
aspect, based on the previous studies, the following factors could be summarized as the major driving or push factors of those migrants: (1) natural environment and natural disasters, (2) increased population and surplus population, (3) commercialization of agricultural products and faded crops, (4) poverty and income differences, (5) accessibility to external society, and (6) sense of value of performance orientation. However, our research based on the cross-sectional statistical analysis at the village level is supporting the above factors but only partially, and definitely shows that no single factor affects on emigration but several factors are functioning simultaneously to create emigration at the village level. In fact, it gives a quite complex structure of socioeconomic factors in the villages having many emigrants. The significant association complex of well-being rather than poverty in village economy produced aggressive movement of emigration in the early stage of modernization, based on the path-analysis of village data in the Meiji era of Japan.

\section{References}

Diplomatic Record Office of the Ministry of Foreign Affairs. Archive. Kaigai ryoken kafu hennou hyou sintatsu ikken (List of Passports Issued and Returned).

—. Archive. Nihon jinmin hawaikoku he dekasegi ikken (List of Japanese Emigrants Workers to Hawaii).

—. Archive. Imin toriatsukainin wo keiyu suru kaigaitokousha meibo (List of Japanese Emigrants via Emigrant Companies).

Editing Committee, History of Municipalities of Shiga Prefecture. 1962. History of Municipalities of Shiga Prefecture. Vol.5. Editing Committee: Otsu.

Fukuda, Toru. 1986. Shiga ken ni okeru hoku-bei imin no kuukan bunseki. (Spatial Distribution of Japanese Emigrants to North America from Shiga Prefecture). In Japanese American, Ed. Muneyoshi Togami. Minerva: Kyoto. 31-55.

Kawamura, Yoshio 2009, Socioeconomic Factor Structure of Japanese Emigrant Communities: Statistical Case Study at Inukami County, Shiga Prefecture, in Meiji Era, Working Paper Series No.50, Afrasian Centre for Peace and Development Studies, Ryukoku Unversity, pp.23.

Kawamura, Yoshio 2017, "Historical Characteristics of Emigration from Rural Japan in the Pre-World War II," Journal of Asian Rural Studies, 1(2), July, pp.109-122.

Kawasaki, Aisaku. 1982. History of Shiga Prefecture Overseas Immigration, Data IIStatistics of Prewar Overseas Immigrants. Ijyu Kenkyu 19: 105-118.

Kim, Jae-On. 1975. Factor Analysis. In SPSS: Statistical Package for Social Sciences, Eds. N Nie et al. McGraw-Hill: New York. 480.

Statistics and Information Department, Ministry of Agriculture, Forestry and Fisheries, ed.1971. Census of Agriculture and Forestry 1970. Association of Agriculture and Forestry Statistics: Tokyo.

Wakatsuki,Yasuo. 1979. Factor Analysis of Regions Producing Many Immigrants to America. Research Paper No.19, Agricultural Department of Tamagawa University, pp.104-123. 